Stephen F. Austin State University

SFA ScholarWorks

Associations between residual feed intake and apparent nutrient digestibility, in vitro methane-producing activity, and volatile fatty acid concentrations in growing beef cattle

Jocelyn R. Johnson

Gordon E. Carstens

Wimberly K. Krueger

Phillip A. Lancaster

Erin G. Brown

See next page for additional authors

Follow this and additional works at: https://scholarworks.sfasu.edu/agriculture_facultypubs

Part of the Agriculture Commons, and the Animal Sciences Commons

Tell us how this article helped you. 


\section{Authors}

Jocelyn R. Johnson, Gordon E. Carstens, Wimberly K. Krueger, Phillip A. Lancaster, Erin G. Brown, Luis O. Tedeschi, Robin C. Anderson, Kristen A. Johnson, and Arieh Brosh 


\title{
Associations between residual feed intake and apparent nutrient digestibility, in vitro methane-producing activity, and volatile fatty acid concentrations in growing beef cattle ${ }^{1}$
}

\author{
Jocelyn R. Johnson, ${ }^{\dagger}$ Gordon E. Carstens, ${ }^{\dagger, 2}$, Wimberly K. Krueger, ${ }^{\dagger}$ Phillip A. Lancaster, ${ }^{\ddagger}$ \\ Erin G. Brown," Luis O. Tedeschi, ${ }^{\dagger}$ Robin C. Anderson ${ }^{\$}$, Kristen A. Johnson, ${ }^{\complement}$ and Arieh Brosh ${ }^{\&}$ \\ †Department of Animal Science, Texas A\&M University, College Station, TX 77843; and Department of Animal \\ Sciences, Missouri State University, Springfield, MO; "Department of Agriculture, Stephen F. Austin State

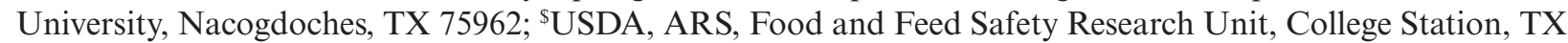 \\ 77845; 'Department of Animal Science, Washington State University, Pullman, WA 99164; \&Beef Cattle Section, \\ Agricultural Research Organization, Ramat Yishay, IL 30950
}

\begin{abstract}
The objectives of this study were to examine the relationship between residual feed intake (RFI) and DM and nutrient digestibility, in vitro methane production, and volatile fatty acid (VFA) concentrations in growing beef cattle. Residual feed intake was measured in growing Santa Gertrudis steers (Study 1; $n=57$; initial $\mathrm{BW}=291.1 \pm 33.8 \mathrm{~kg}$ ) and Brangus heifers (Study $2 ; n=468$; initial BW $=271.4 \pm 26.1 \mathrm{~kg}$ ) fed a highroughage-based diet $(\mathrm{ME}=2.1 \mathrm{Mcal} / \mathrm{kg} \mathrm{DM})$ for $70 \mathrm{~d}$ in a Calan-gate feeding barn. Animals were ranked by RFI based on performance and feed intake measured from day 0 to 70 (Study 1) or day 56 (Study 2) of the trial, and 20 animals with the lowest and highest RFI were identified for subsequent collections of fecal and feed refusal samples for DM and nutrient digestibility analysis. In Study 2, rumen fluid and feces were collected for in vitro methane-producing activity (MPA) and VFA analysis in trials 2, 3, and 4. Residual feed intake classification did not affect $\mathrm{BW}$ or $\mathrm{BW}$ gain $(P>0.05)$, but low-RFI steers and heifers both consumed $19 \%$ less $(P<0.01)$ DMI compared with high-RFI animals. Steers with low RFI tended $(P<0.1)$ to have higher DM digestibility (DMD) compared with high-RFI steers (70.3 vs.

$66.5 \pm 1.6 \%$ DM). Heifers with low RFI had 4\% higher DMD (76.3 vs. $73.3 \pm 1.0 \% \mathrm{DM})$ and 4 to $5 \%$ higher $(P<0.01) \mathrm{CP}, \mathrm{NDF}$, and ADF digestibility compared with heifers with high RFI. Low-RFI heifers emitted $14 \%$ less $(P<0.01)$ methane ( $\%$ GE intake; GEI) calculated according to Blaxter and Clapperton (1965) as modified by Wilkerson et al. (1995), and tended $(P=0.09)$ to have a higher rumen acetate:propionate ratio than heifers with high RFI (GEI $=5.58$ vs. $6.51 \pm 0.08 \%$; A:P ratio $=5.02$ vs. $4.82 \pm 0.14 \%$ ) Stepwise regression analysis revealed that apparent nutrient digestibilities (DMD and NDF digestibility) for Study 1 and Study 2 accounted for an additional 8 and $6 \%$, respectively, of the variation in intake unaccounted for by $\mathrm{ADG}$ and mid-test $\mathrm{BW}^{0.75}$. When DMD, NDF digestibility, and total ruminal VFA were added to the base model for Study 2, trials 2, 3, and 4, the $R^{2}$ increased from 0.33 to 0.47 , explaining an additional $15 \%$ of the variation in DMI unrelated to growth and body size. On the basis of the results of these studies, differences in observed phenotypic RFI in growing beef animals may be a result of inter-animal variation in apparent nutrient digestibility and ruminal VFA concentrations.
\end{abstract}

Key Words: cattle efficiency, digestibility, forage, methane, residual feed intake, volatile fatty acid

\footnotetext{
${ }^{1}$ This study was supported by grant IS-39988-07 from BARD, the United States Israel Binational Agricultural Research and Development Fund.

${ }^{2}$ Corresponding author: g-carstens@tamu.edu

Received March 1, 2019.

Accepted June 6, 2019.
} 
(C) The Author(s) 2019. Published by Oxford University Press on behalf of the American Society of Animal Science. All rights reserved. For permissions, please e-mail: journals.permissions@oup.com.

J. Anim. Sci. 2019.97:3550-3561 doi: 10.1093/jas/skz195

\section{INTRODUCTION}

Profitability of a cattle operation depends on the efficient use of feed to meet nutrient requirements as feed accounts for the single largest variable input cost associated with producing cattle. Residual feed intake is an ideal trait to use in selection programs to improve feed efficiency as it is a moderately heritable trait (Schenkel et al., 2004) that quantifies an animals' feed efficiency independent of growth or body size. Residual feed intake is defined as the difference between an animal's actual and predicted intake based on growth and body size. Efficient or low-residual feed intake (RFI) animals have reduced feed intake compared with animals with equal growth and body size (Nkrumah et al., 2004; Lancaster et al., 2009; Hafla et al., 2013; Baldassini et al., 2018; Lam et al., 2018) and decreased methane emissions (Hegarty et al., 2007; Basarab et al., 2013) compared with their inefficient or high-RFI counterparts.

Specific biological mechanisms contributing to differences in observed phenotypic RFI have yet to be fully understood. Current literature has identified relationships between protein turnover, tissue metabolism, stress, digestibility, heat increment, fermentation, physical activity, body composition, and feeding patterns (Richardson and Herd, 2004; Nkrumah et al., 2007; Lancaster et al., 2009; Kayser and Hill, 2013; Cantalapiedra-Hijar et al., 2018). Herd et al. (2004) estimated that approximately $14 \%$ of the biological variation in RFI was associated with differences in digestion and its processes in growing animals of divergent RFI phenotypes. However, literature has been inconsistent regarding the associations between RFI and dry matter digestibility (DMD; Kenny et al., 2018). Nevertheless, several studies have identified a negative relationship between RFI and DMD (Richardson et al., 1996; Nkrumah et al., 2006; Bonilha et al., 2017), indicating that inter-animal variation in RFI may be due to differences in digestibility. In a recent meta-analysis conducted by Cantalapiedra-Hijar et al. (2018), differences in digestibility of cattle with divergent RFI appear to be related to the level of intake as a negative correlation was found between DMD and dry matter intake (DMI).

However, further research is needed to determine whether the apparent improvements in DMD are simply a function of slower passage rage of digesta through the rumen due to lower DMI or improved digestive ability of more feed-efficient animals (Kenny et al., 2018). Furthermore, few studies have examined the effects of RFI on fermentation parameters and nutrient digestibility in growing calves fed a high-roughage diet. Therefore, the objectives of these studies were to quantify differences in nutrient digestibility, examine ruminal and fecal VFA profiles, and estimate in vitro methaneproducing activity (MPA) in growing calves with divergent phenotypes for RFI.

\section{MATERIALS AND METHODS}

\section{Animals and Management}

All animal care and use procedures were in accordance with the guidelines for the use of Animals in Agricultural Teaching and Research as approved by the Texas A\&M University Institutional Animal Care and Use Committee (approval number 2006180 and 2001-249AG). The experimental animals used in Study 1 consisted of 57 Santa Gertrudis steers (King Ranch, Kingsville, TX) with initial $\mathrm{BW}$ and age of $273 \pm 29 \mathrm{~kg}$ and $238 \pm 16 \mathrm{~d}$, respectively, and Study 2 consisted of 4 trials utilizing 468 Brangus heifers (Camp Cooley Ranch, Franklin, TX) with initial BW and age of $271 \pm 26 \mathrm{~kg}$ and $231 \pm 12 \mathrm{~d}$, respectively. Study 2 trials were conducted in consecutive years $(n=114$ in year 1 , $n=115$ in year 2, $n=119$ in year 3, $n=120$ in year 4). All trials were conducted at the O.D. Butler, Jr. Animal Science Complex (College Station, TX).

Upon arrival, animals were blocked by BW, randomly assigned to pens equipped with Calangate feeders $(6 \mathrm{hd} / \mathrm{pen})$, and adapted to a total mixed ration (2.13 Mcal ME/kg DM and $11.2 \%$ CP DM in Study 1; $1.98 \mathrm{Mcal} \mathrm{ME} / \mathrm{kg}$ DM and $12.7 \%$ CP DM in Study 2; Table 1) consisting of chopped alfalfa, alfalfa pellets, cottonseed hulls, dry rolled corn, and molasses for a minimum of 24 d. For Study 1, a premix was included in the total mixed ration that contained monensin, tylosin, in combination with vitamins and minerals, and in Study 2, a trace mineral premix was fed in combination with vitamin $\mathrm{E}$ and salt. Following adaptation, animals were fed twice daily (0800 and 1400 ) to target $10 \%$ feed refusals, and ad libitum feed intakes were recorded daily for individual 
Table 1. Ingredient and chemical composition of the diets used in Santa Gertrudis steers (Study 1) and Brangus heifers (Study 2)

\begin{tabular}{lcc}
\hline \hline Item & Study 1 diet & Study 2 diets \\
\hline Ingredient composition, \% as-fed basis & \\
Chopped alfalfa & 35.0 & 35.0 \\
Pelleted alfalfa & 19.0 & 15.0 \\
Dry rolled corn & 15.5 & 21.0 \\
Cottonseed hulls & 21.5 & 21.5 \\
Molasses & 7.00 & 7.00 \\
Premix & - \\
Salt & 2.00 & 0.40 \\
Vitamin E & - & 0.14 \\
Trace mineral & - & 0.02 \\
Chemical composition & - & \\
DM, \% & & 87.9 \\
ME, Mcal/kg DM & 87.1 & 1.98 \\
CP, \% of DM & 2.13 & 12.7 \\
NDF, \% of DM & 11.2 & 45.6 \\
ADF, \% of DM & 41.4 & 32.3 \\
P, \% of DM & 32.0 & 0.25 \\
Ca, \% of DM & 0.27 & 0.86 \\
\hline
\end{tabular}

${ }^{1}$ Chemical analysis for Study 2 represents the average of diets used in each of the 4 trials.

${ }^{2}$ Premix for Study 1 contained $1.66 \mathrm{~g} / \mathrm{kg}$ monensin, $0.55 \mathrm{~g} / \mathrm{kg}$ tylosin, $675 \mathrm{mg} / \mathrm{kg} \mathrm{Cu}, 1050 \mathrm{mg} / \mathrm{kg} \mathrm{Mn}, 2850 \mathrm{mg} / \mathrm{kg} \mathrm{Zn}, 15 \mathrm{mg} / \mathrm{kg} \mathrm{Se}, 35 \mathrm{mg} / \mathrm{kg}$ I, $7.5 \mathrm{mg} / \mathrm{kg} \mathrm{Co}, 132,300 \mathrm{IU} / \mathrm{kg}$ vitamin A, and $3308 \mathrm{IU} / \mathrm{kg}$ vitamin $\mathrm{E}$.

${ }^{3}$ Vitamin E contained 44,000 IU/kg product.

${ }^{4}$ Trace mineral contained a minimum of $19.0 \% \mathrm{Zn}, 7.0 \% \mathrm{Mn}, 4.5 \%$ $\mathrm{Cu}, 4,000$ ppm Fe, 2,300 ppm I, 1,000 ppm Se, and 500 ppm Co.

${ }^{5}$ Metabolizable energy content computed using Cornell Net Carbohydrate and Protein System.

animals. For each trial, BW and feed refusals' were collected at 7-d intervals. Linear regression (PROC GLM, SAS Institute Inc., Cary, NC) of BW on the day of trial was used to determine ADG, initial and final BW, and mid-test $\mathrm{BW}^{0.75}$. Residual feed intake was computed for each study as the difference between actual and expected DMI from the linear regression of mean DMI on mid-test $\mathrm{BW}^{0.75}$ and ADG as described by Koch et al. (1963). For Study 2, the trial was included as a fixed effect in the model. Average daily gain and mid-test $\mathrm{BW}^{0.75}$ accounted for $60 \%$ of the variation in DMI for Study 1 , and $54 \%$ of the variation in DMI for Study 2. For Study 1, steers were ranked by RFI using performance and feed intake data collected from days 0 to 70 of the trial, and the steers with lowest $(n=20)$ and highest $(n=20)$ RFI identified for subsequent collection of fecal and feed refusal samples from days 70 to 76 . The steers with divergent RFI were \pm 0.55 SD from the mean RFI of $-0.02 \pm 0.85 \mathrm{~kg} \mathrm{DM} / \mathrm{d}(n=57)$. In Study 2 , RFI was computed based on data collected during the first $56 \mathrm{~d}$, as the trial timelines did not permit fecal and feed refusal sampling procedures to take place following the completion of the trial on $\mathrm{d}$ 70. Accordingly, for each trial, 20 heifers with the lowest RFI, and 20 heifers with the highest RFI based on $56 \mathrm{~d}$ data, were identified for subsequent collection of fecal and feed refusal samples from days 62 to 68 of the trials. The heifers with divergent RFI were $\pm 1.1 \mathrm{SD}$ from the mean RFI of $0.00 \pm 0.69 \mathrm{~kg} \mathrm{DM} / \mathrm{d}(n=468)$. Subsequent analysis of RFI based on performance and feed intake data collected for $70 \mathrm{~d}$ revealed that 5 heifers were no longer classified as having divergent RFI phenotypes, and so were excluded from the study. Additionally, insufficient fecal samples resulted in the exclusion of an additional 3 animals in Study 1, and 8 animals in Study 2.

\section{Estimates of Digestibility}

Fecal samples were collected by rectal palpation once daily at 0700 for 7 consecutive days from days 70 to 76 in Study 1, and from days 62 to 68 in Study 2, and stored at $320^{\circ} \mathrm{C}$. During the fecal collection period, diet feed ingredient samples, and feed refusals' from individual animals were collected and weighed daily. Feed ingredient, diet, fecal, and feed refusals samples were freeze dried (Studies 1 and 2 - trials 1, 2, and 3) or dried in a forced-air oven at $105{ }^{\circ} \mathrm{C}$ (Study 2-trial 4), ground through a $1-\mathrm{mm}$ screen in a Wiley Mill, and composited by weight for subsequent chemical analysis.

\section{VFA, Methane, and pH Analysis}

For trials 2, 3, and 4 (Study 2), rumen fluid and fecal samples were collected from days 62 to 68 to determine VFA concentrations, methane-producing activity, and $\mathrm{pH}$. Prior to morning feedings, rumen fluid was collected via a stomach tube into $50-\mathrm{mL}$ vials that were filled to capacity, and immediately capped and stored at ambient temperature until subsequent analysis within 2 to $3 \mathrm{~h}$. Methaneproducing activity of ruminal and fecal samples was determined by in vitro incubation. Rumen fluid $(5 \mathrm{~mL})$ and fecal $(2 \mathrm{~g})$ samples were mixed with 5 and $8 \mathrm{~mL}$, respectively, anaerobic dilution solution (Bryant and Burkey, 1953) containing $60 \mathrm{mM}$ sodium formate and $0.2 \mathrm{~g}$ finely ground alfalfa (to pass a $4 \mathrm{~mm}$ screen). The tubes were capped and incubated at $39{ }^{\circ} \mathrm{C}$ under a hydrogen:carbon dioxide (50:50) atmosphere. At the end of the incubation period, methane concentration was determined by gas chromatography, according to Allison et al. (1992). 
For VFA analysis, rumen fluid $(1 \mathrm{~mL})$ and fecal $(1 \mathrm{~g})$ samples were diluted 1:10 with water $(\mathrm{pH}=7.0)$ and $\mathrm{pH}$ was recorded. Samples were centrifuged and the supernatant frozen $\left(-20^{\circ} \mathrm{C}\right)$ for subsequent VFA analysis. Volatile fatty acids were analyzed via gas chromatography (Agilent 6890N, Santa Clara, CA) with a 007 series bonded phase fused silica capillary column $(25 \mathrm{~m} \times 0.25 \mathrm{~mm} \times 0.25 \mu \mathrm{m})$ with a flame ionizing detector as described by Erwin et al. (1961). The analysis was performed with the following parameters: $1 \mu \mathrm{l}$ injection, injector temperature $=240^{\circ} \mathrm{C}$, oven temperature $=80^{\circ} \mathrm{C}$ for $1 \mathrm{~min}$, ramp to $120^{\circ} \mathrm{C}$ hold for $5 \mathrm{~min}$, ramp to $165^{\circ} \mathrm{C}$ hold for $2 \mathrm{~min}$, detector temperature $=260^{\circ} \mathrm{C}$.

\section{Chemical Analysis and Calculations}

Acid-insoluble ash (AIA) was used as an internal marker to estimate digestibility coefficients using fecal and feed refusal composite samples for individual animals, and feed ingredient composite samples for each diet. AIA was determined according to Vankeulen and Young (1977) using $2 \mathrm{~N}$ hydrochloric acid digestion and ashing, and was analyzed according to Van Soest et al. (1991) using the ADF procedure and subsequent ashing. Neutral detergent fiber and ADF were determined using an ANKOM Fiber Analyzer F200 (ANKOM Technology Corporation, Fairport, NY) according to manufacturer's protocol with the exception that sodium sulfite was not added in the NDF procedure (ANKOM, 2006a, 2006b). Nitrogen was determined using a LECO FP2000 nitrogen analyzer (LECO Corporation, St. Joseph, MI) and CP was calculated by multiplying the total $\mathrm{N}$ by a factor of 6.25. Mineral analysis was determined using ICP analysis of a nitric acid digest. Metabolizable energy concentrations of the experimental diets were computed from chemical analysis using the Cornell Net Carbohydrate and Protein System (Version 5.0, Cornell University, Ithaca, NY). Methane emission as a proportion of gross energy intake (GEI) was calculated according to Blaxter and Clapperton (1965) as modified by Wilkerson et al. (1995).

\section{Statistical Analysis}

The effect of RFI classification on performance, feed efficiency, and apparent nutrient digestibility was analyzed for each study using the MIXED Procedure of SAS according to a model that included the fixed effect of RFI classification, and for Study 2 the random effect of trial. Mean separation was accomplished using the Tukey-Kramer option in SAS.
The MIXED Procedure of SAS was also used to determine whether the level of feed intake accounted for variation in DMD according to a model that included DMI as a covariate, the fixed effect of RFI classification, and RFI classification by DMI interaction, and for Study 2, the random effect of trial and trial by DMI interaction. To generate phenotypic correlation coefficients performance, feed efficiency, and digestibility, traits in Study 2 were adjusted for the random effect of trial using the fit model platform of JMP (SAS Institute Inc., Cary, NC). Variables adjusted for the random effects of trial from Study 2, and unadjusted variables for Study 1, were then used in the multivariate platform of JMP (SAS Institute Inc.) to obtain phenotypic correlations. For this study, $P$-values $\leq 0.05$ were considered significant, and values $\leq 0.10$ were considered tendencies.

A two-step approach was used to determine whether individual-animal variation in apparent nutrient digestibilities accounted for variation in RFI. First, stepwise regression analysis was performed (PROC REG of SAS) to determine the order of inclusion of digestibility and ruminal fermentation parameters to the base model used to calculate RFI, which included mid-test $\mathrm{BW}^{0.75}$ and ADG. Parameters were removed from the model if they were not significant at the 0.10 level. Secondly, based on results from stepwise analysis, traits were sequentially added to the base model, and the change in coefficient of determination used to determine their relative importance.

$$
\begin{aligned}
Y_{i j}= & \beta_{0}+\beta_{1} \text { mid }- \text { test } \mathrm{BW}^{0.75}{ }_{i j} \\
& +\beta_{2} \mathrm{ADG}_{i j}+\beta_{x} \mathrm{X}_{i j k}+R_{i}+\varepsilon_{i j},
\end{aligned}
$$

where $Y_{i j}$ is the DMI of the $j$ th heifer in the $i$ th trial, $X_{i j k}$ is the $k$ th digestibility parameter for the $j$ th heifer in the $i$ th trial, $\beta_{0}$ is the regression intercept, $\beta_{1}$ is the regression coefficient on mid-test $\mathrm{BW}^{0.75}$, $\beta_{2}$ is the regression coefficient on ADG, $\beta_{x}$ is the regression coefficient for digestibility parameter $X$, $R_{i}$ is the random effect of $i$ th trial and significant trial $\times$ independent variable interactions, and $\varepsilon_{i j}$ is the random uncontrolled error for the $j$ th heifer in the $i$ th trial.

\section{RESULTS}

\section{Study 1}

Digestibility estimates from Study 1 are presented in Table 2. There was a tendency $(P=0.10)$ for steers with low RFI to have $6 \%$ higher DMD compared with 
Table 2. Performance, feed efficiency, feed intake, and apparent nutrient digestibility estimates for Santa Gertrudis steers with low- and high-RFI phenotypes from Study 1

\begin{tabular}{|c|c|c|c|c|c|c|}
\hline Item $^{1}$ & Mean & SD & Low RFI & High RFI & SE & $P$-value \\
\hline No. of animals ${ }^{2}$ & 57 & & 18 & 19 & & \\
\hline \multicolumn{7}{|c|}{ Performance traits (70-d period) } \\
\hline Initial BW, kg & 304 & 29 & 305 & 309 & 7 & 0.69 \\
\hline Final BW, kg & 396 & 34 & 397 & 407 & 8 & 0.33 \\
\hline $\mathrm{ADG}, \mathrm{kg} \mathrm{d}^{-1}$ & 1.20 & 0.20 & 1.19 & 1.28 & 0.05 & 0.19 \\
\hline DMI, $\mathrm{kg} \mathrm{d}^{-1}$ & 9.97 & 1.32 & 9.05 & 11.20 & 0.23 & 0.01 \\
\hline \multicolumn{7}{|l|}{ Feed efficiency (70-d period) } \\
\hline RFI, $\mathrm{kg} \mathrm{d}^{-1}$ & -0.020 & 0.850 & -0.990 & 0.880 & 0.100 & 0.01 \\
\hline $\mathrm{G}: \mathrm{F}$ & 0.125 & 0.018 & 0.130 & 0.110 & 0.010 & 0.01 \\
\hline \multicolumn{7}{|c|}{ Feed intake (fecal collection period) $)^{3}$} \\
\hline DMI, kg/d & 10.6 & 1.8 & 9.5 & 11.6 & 0.4 & 0.01 \\
\hline Feed refusals \% DMI & 11.2 & 8.3 & 15.1 & 7.5 & 1.8 & 0.01 \\
\hline Feed refusal CP, \% DM & 14.8 & 1.3 & 15.1 & 14.5 & 0.3 & 0.10 \\
\hline Feed refusal NDF, \% DM & 44.5 & 4.0 & 44.6 & 44.5 & 1.0 & 0.95 \\
\hline \multicolumn{7}{|l|}{ Apparent nutrient digestibility ${ }^{3}$} \\
\hline $\mathrm{DM}, \%$ & 68.4 & 7.1 & 70.3 & 66.5 & 1.6 & 0.10 \\
\hline $\mathrm{CP}, \%$ & 57.6 & 10.0 & 59.7 & 55.5 & 2.3 & 0.21 \\
\hline NDF, $\%$ & 52.1 & 10.5 & 54.8 & 49.6 & 2.4 & 0.13 \\
\hline
\end{tabular}

${ }^{1}$ Feed refusals', \% DMI = [(feed refusals' DM/DMI $\left.) \times 100\right]$.

${ }^{2}$ Animals with divergent RFI were \pm 0.55 SD from the mean.

${ }^{3}$ Data represent the 37 animals with divergent RFI identified for subsequent digestibility analsysis.

high-RFI steers. However, apparent CP and NDF digestibility was not different $(P>0.10)$ between steers with divergent RFI. During the 7-d fecal collection period, steers with high RFI had less $(P<0.05)$ feed refusals as a percentage of DMI (Table 2). However, no differences $(P>0.10)$ were found between the $\mathrm{CP}$ and NDF concentration of feed refusal samples between low- and high-RFI steers.

Phenotypic correlations among traits measured in Study 1 are presented in Table 4 (below diagonal). As expected, RFI was not correlated with initial BW or ADG, but was positively correlated $(P<0.05)$ with DMI. Residual feed intake was negatively correlated $(P<0.05)$ with DMD; however, no significant correlations $(P>0.05)$ were observed between RFI and CP or NDF digestibility.

Mid-test $\mathrm{BW}^{0.75}$ and $\mathrm{ADG}$ accounted for $54 \%$ of the variation in individual-animal DMI based on multiple linear regression. Upon addition of DMD to the base RFI model (ADG and mid-test $\left.\mathrm{BW}^{0.75}\right), R^{2}$ was increased from 0.54 to 0.60 . Dry matter digestibility, but not $\mathrm{CP}$ or NDF digestibility, was found to be a significant source of variation $(P<0.10)$.

\section{Study 2}

Digestibility estimates for Study 2 are presented in Table 3. Low-RFI animals in Study 2 had higher
$(P=0.01) \mathrm{CP}, \mathrm{NDF}, \mathrm{ADF}$, and $\mathrm{P}$ digestibilities compared with their high-RFI cohorts. Digestibility coefficients for heifers with low RFI tended to be higher $(P<0.06)$ for $\mathrm{Ca}$ and $\mathrm{Cu}$ compared with heifers with high RFI. Differences in Zn digestibility between heifers with low and high RFI were not detected $(P=0.57)$. Residual feed intake was correlated [Table 4 (above diagonal); $(P<0.05)$ ] with $\mathrm{DMI}(r=0.80), \mathrm{DMD}(r=-0.25), \mathrm{CP}$ digestibility $(r=-0.27)$, and NDF digestibility $(r=-0.21)$ in heifers from Study 2.

During the 7-d fecal collection periods, highRFI animal's had $27 \%$ less $(P<0.01)$ feed refusals' as a proportion of DMI than low-RFI cattle (Table $3)$. However, CP, NDF, and ADF concentrations of feed refusal samples were not affected $(P>0.20)$ by the RFI phenotype group.

Ruminal and fecal $\mathrm{pH}$, in vitro MPA, calculated methane losses, and ruminal VFA concentrations from heifers in trials 2, 3, and 4 are presented in Table 5. Differences between low- and high-RFI heifers in ruminal and fecal $\mathrm{pH}$ and in vitro MPA were not detected $(P>0.42)$. However, estimates of methane energy losses expressed as a proportion of GEI (Blaxter and Clapperton, 1965) were less $(P<0.01)$ for heifers with low RFI. There were no differences $(P>0.21)$ in ruminal acetate or butyrate concentrations; however, ruminal propionate concentrations were lower $(P=0.04)$ in heifers with 
Table 3. Performance, feed efficiency, feed intake, and apparent nutrient digestibility estimates for Brangus heifers with low- and high-RFI phenotypes from Study 2 (4 trials; $n=468$ )

\begin{tabular}{|c|c|c|c|c|c|c|}
\hline Item $^{1}$ & Mean & SD & Low RFI & High RFI & SE & $P$-value \\
\hline No. of animals ${ }^{2}$ & 468 & & 74 & 73 & & \\
\hline \multicolumn{7}{|c|}{ Performance traits ( $70-\mathrm{d}$ period) } \\
\hline Initial BW, kg & 271 & 27 & 274.2 & 269.8 & 7.97 & 0.29 \\
\hline Final BW, kg & 342 & 30 & 344.6 & 342.4 & 4.95 & 0.66 \\
\hline $\mathrm{ADG}, \mathrm{kg} \mathrm{d}^{-1}$ & 1.01 & 0.17 & 1.01 & 1.05 & 0.05 & 0.23 \\
\hline DMI, $\mathrm{kg} \mathrm{d}^{-1}$ & 9.46 & 1.04 & 8.55 & 10.6 & 0.14 & 0.01 \\
\hline \multicolumn{7}{|l|}{ Feed efficiency (70-d period) } \\
\hline $\mathrm{RFI}, \mathrm{kg} \mathrm{d}^{-1}$ & 0.000 & 0.690 & -0.945 & 1.029 & 0.06 & 0.01 \\
\hline $\mathrm{G}: \mathrm{F}$ & 0.110 & 0.017 & 0.118 & 0.099 & 0.01 & 0.01 \\
\hline \multicolumn{7}{|c|}{ Feed intake (fecal collection period) ${ }^{3}$} \\
\hline DMI, kg/d & 9.7 & 1.6 & 8.7 & 10.7 & 0.2 & 0.01 \\
\hline Feed refusals $\%$ DMI & 10.9 & 6.8 & 12.8 & 9.4 & 0.78 & 0.01 \\
\hline Feed refusal CP, $\%$ DM & 13.5 & 1.9 & 13.2 & 13.6 & 0.49 & 0.17 \\
\hline Feed refusal NDF, \% DM & 43.2 & 7.2 & 43 & 43.7 & 1.4 & 0.54 \\
\hline \multicolumn{7}{|l|}{ Apparent nutrient digestibility ${ }^{3}$} \\
\hline DM, $\%$ & 74.7 & 7.8 & 76.3 & 73.3 & 1.0 & 0.01 \\
\hline $\mathrm{CP}, \%$ & 70.8 & 9.0 & 72.7 & 69.1 & 1.1 & 0.01 \\
\hline NDF, $\%$ & 69.0 & 9.8 & 70.7 & 67.6 & 1.2 & 0.01 \\
\hline $\mathrm{ADF}, \%$ & 65.7 & 9.7 & 67.5 & 64.2 & 1.2 & 0.01 \\
\hline Phosphorus, \% & 59.7 & 16.1 & 61.9 & 57.6 & 1.8 & 0.01 \\
\hline Calcium, $\%$ & 54.2 & 12.1 & 56.3 & 52.2 & 1.8 & 0.06 \\
\hline Zinc, $\%$ & 50.7 & 15.2 & 53.2 & 51.5 & 3.0 & 0.57 \\
\hline Copper, $\%$ & 59.4 & 13.3 & 61.8 & 57.9 & 1.7 & 0.05 \\
\hline
\end{tabular}

${ }^{1}$ Feed refusals', \% DMI $=[($ feed refusals' DM/DMI $) \times 100]$.

${ }^{2}$ Animals with divergent RFI were $\pm 1.1 \mathrm{SD}$ from the mean.

${ }^{3}$ Data represents the 37 animals with divergent RFI identified for subsequent digestibility analysis.

Table 4. Phenotypic correlations among performance and feed efficiency traits, and nutrient digestibility estimates in Santa Gertrudis steers with low $(n=18)$ and high $(n=19)$ RFI phenotypes from Study 1 (below diagonal) and Brangus heifers with low $(n=74)$ and high $(n=73)$ RFI phenotypes from Study 2 (above diagonal)

\begin{tabular}{|c|c|c|c|c|c|c|c|}
\hline Trait $^{1}$ & $\mathrm{ADG}$ & DMI & RFI & $\mathrm{G}: \mathrm{F}$ & DMD & CPD & NDFD \\
\hline$\overline{\mathrm{ADG}}$ & - & $0.50 *$ & 0.03 & $0.61 *$ & 0.04 & 0.04 & 0.03 \\
\hline DMI & $0.64 *$ & - & $0.80^{*}$ & $-0.36^{*}$ & $-0.16^{*}$ & $-0.17^{*}$ & -0.13 \\
\hline RFI & 0.24 & $0.83^{*}$ & - & $-0.70^{*}$ & $-0.25^{*}$ & $-0.27^{*}$ & $-0.21^{*}$ \\
\hline G:F & $0.57^{*}$ & -0.26 & $-0.58^{*}$ & - & $0.23^{*}$ & $0.24 *$ & 0.18 \\
\hline DMD & -0.08 & -0.23 & $-0.35^{*}$ & 0.16 & - & $0.98^{*}$ & $0.98^{*}$ \\
\hline CPD & 0.01 & -0.14 & -0.27 & 0.16 & $0.95^{*}$ & - & $0.95^{*}$ \\
\hline NDFD & -0.02 & -0.19 & -0.33 & 0.19 & $0.99 *$ & $0.94^{*}$ & - \\
\hline
\end{tabular}

${ }^{1} \mathrm{DMD}=$ apparent dry matter digestibility, NDFD = NDF digestibility, $\mathrm{CPD}=$ apparent $\mathrm{CP}$ digestibility.

*Correlations are different from zero at $P<0.05$.

low RFI. There were no differences $(P>0.15)$ observed in fecal VFA concentrations amongst heifers with divergent RFI.

For Study 2, trials 1, 2, 3, and $4(n=147)$, mid-test $\mathrm{BW}^{0.75}$ and ADG accounted for $32 \%$ of the variation in individual-animal DMI for heifers with divergent RFI. Upon addition of DMD and NDF digestibility to the base RFI model (ADG and mid-test $\left.\mathrm{BW}^{0.75}\right), R^{2}$ was increased from 0.32 to 0.40 . Dry matter digestibility and NDF digestibility, but not $\mathrm{CP}$ digestibility, were found to be significant sources of variation $(P<0.10)$. For Study 2, trials 2, 3, and 4, mid-test $\mathrm{BW}^{0.75}$ and ADG accounted for $29 \%$ of the variation in DMI. When DMD, NDF digestibility, and total ruminal VFA were added to the base RFI model for these trials in Study 2, $R^{2}$ increased from 0.33 to 0.47 . 
Table 5. Fermentation parameters in Brangus heifers with low $(n=52)$ and high $(n=51)$ RFI phenotypes from trials 2, 3, and 4 of Study 2

\begin{tabular}{|c|c|c|c|c|}
\hline Item & Low RFI & High RFI & SE & $P$-value \\
\hline Rumen $\mathrm{pH}^{1}$ & 7.11 & 7.08 & 0.06 & 0.74 \\
\hline Fecal $\mathrm{pH}^{1}$ & 7.26 & 7.24 & 0.09 & 0.84 \\
\hline Rumen methane ${ }^{2}$ & 11.6 & 10.9 & 0.85 & 0.42 \\
\hline Fecal methane ${ }^{2}$ & 0.77 & 0.71 & 0.16 & 0.74 \\
\hline Methane $^{3}, \%$ GE & 5.58 & 6.51 & 0.08 & 0.01 \\
\hline Ruminal acetate & 40.4 & 43.9 & 2.71 & 0.21 \\
\hline Fecal acetate & 36.0 & 33.9 & 1.97 & 0.29 \\
\hline Ruminal propionate & 8.14 & 9.26 & 0.53 & 0.04 \\
\hline Fecal propionate & 8.87 & 8.77 & 0.48 & 0.84 \\
\hline Ruminal butyrate & 6.90 & 7.19 & 0.57 & 0.61 \\
\hline Fecal butyrate & 4.49 & 4.51 & 0.32 & 0.94 \\
\hline Total ruminal VFA & 55.5 & 60.3 & 3.71 & 0.20 \\
\hline Total fecal VFA & 49.4 & 47.2 & 2.63 & 0.41 \\
\hline Ruminal A:P ratio ${ }^{4}$ & 5.02 & 4.82 & 0.12 & 0.09 \\
\hline Fecal A:P ratio ${ }^{4}$ & 4.07 & 3.87 & 0.14 & 0.15 \\
\hline
\end{tabular}

\footnotetext{
${ }^{1}$ Rumen and fecal pH: low and high RFI ( $n=36$ and 34); only measured in trials 3 and 4.

${ }^{2}$ Rumen and fecal methane: low and high RFI ( $n=50$ and 48$)$.

${ }^{2}$ In vitro methane-producing activity ( $\mu \mathrm{mol} \mathrm{CH}_{4} / \mathrm{mL}$ fermentation fluid).

${ }^{3}$ Calculated using Blaxter and Clapperton (1965) as modified by Wilkerson et al. (1995); DMI was a significant covariate $(P<0.001)$.

${ }^{4}$ Acetate:propionate ratio.
}

Dry matter digestibility was correlated [data not shown; $P<0.05$ ] with ruminal and fecal MPA $(r=0.50 ; r=-0.23$, respectively), ruminal total VFA $(r=-0.2)$, and DMI $(r=-0.25)$. As expected, diet and nutrient digestibilities were negatively correlated $(P<0.05)$ with methane GEI.

\section{DISCUSSION}

\section{Apparent Nutrient Digestibilities}

There is growing evidence that genetic variation exists in RFI of growing beef cattle (Herd and Bishop, 2000; Nkrumah et al., 2007; Moore et al., 2009; Basarab et al., 2013; Cantalapiedra-Hijar et al., 2018). While the biological basis for variation in RFI is not fully understood, the current study provides evidence that differences in nutrient digestibility may contribute to inter-animal variation in RFI.

For this experiment, low-RFI animals tended to or had lower DMD compared with high-RFI animals. Similar results have been reported for animals consuming high-roughage diets as low-RFI Angus heifers and bulls consuming a 70\% lucerne hay: 30\% wheat mixture tended $(P<0.10$; Richardson et al., 1996) to have higher DMD and low-RFI dairy cattle consuming ryegrass had higher $(P<0.05$; Rius et al., 2012) DMD than their high-RFI counterparts. Additionally, DMD of Sahiwal calves was found to differ between animals with divergent RFI consuming a high-roughage TMR, such that DMD of low-RFI calves was $8 \%$ higher than that observed in high-RFI calves (Sharma et al., 2018). However, when heifers consumed a grass silage diet, no differences in DMD were found between lowand high-RFI cattle (Lawrence et al., 2011, 2012, 2013; Fitzsimons et al., 2013). When various diets were compared within studies, low-RFI lactating cows had higher $(P<0.01$; Potts et al., 2017) and beef heifers tended $(P<0.10$; McDonnell et al., 2016) to have higher DMD when consuming lowstarch, but not high-starch diets, compared to their high-RFI counterparts. For each of these previous studies, no differences were observed in DMD in cattle consuming high-starch diets. Results from these studies indicate that RFI effects on DMD may be less when a high-grain vs. a high-roughage diet is fed to cattle. In support of this idea, numerous studies have found no differences in DMD across RFI phenotypes when high-grain diets were fed (Richardson et al., 2004; Cruz et al., 2010; Gomes et al., 2013; Lawrence et al., 2013). However, when Nkrumah et al. (2006) pair-fed steers a high-grain feedlot diet, DMD tended $(P=0.10)$ to be lower in low-RFI steers compared with high-RFI steers. Additionally, low-RFI feedlot bulls tended to have increased DMD compared with their high-RFI counterparts when consuming a high-grain diet (Bonilha et al., 2017). 
In the current study, heifers in Study 2 had higher NDF digestibility indicating an increased capacity of low-RFI animals to digest high fiber diets. Potts et al. (2017) observed a similar relationship in lactating Holstein cows as low-RFI animals tended $(P<0.10)$ to have higher NDF digestibility when consuming low-starch diets. However, when these lactating dairy cows were fed high-starch diets, no differences were observed in NDF digestibility across RFI phenotypes (Potts et al., 2017). The authors indicated that the relationship between RFI and digestibility was, therefore, dependent on diet, but conflicting results were reported by Bonilha et al. (2017) for finishing Nellore bulls consuming a high-grain diet as they found a $19 \%$ increase $(P<0.05)$ in the NDF digestibility, corrected for ash and protein, of low-RFI bulls compared to their high-RFI counterparts. Given the discrepancy between animal models used in the previously discussed studies, it is difficult to draw conclusions regarding the effect of diet on the associations between RFI and digestibility. However, for highstarch diets, effects of RFI on DMD may not be as consistently observed as postruminal starch digestion may compensate for reductions in the ruminal starch digestion resulting from reduced ruminal retention times in high-RFI cattle. Accordingly, diet type may alter the associations between RFI and digestibility.

In the current study, CP digestibility was higher for low-RFI heifers in Study 2, but was not for steers in Study 1 compared with their high-RFI counterparts. Previous studies have reported a significant relationship between RFI and protein digestibility with low-RFI lactating cows having higher $(P<0.05$; Rius et al., 2012) and beef steers tending towards $(P<0.10$; Nkrumah et al., 2006) higher protein digestibilities. However, Potts et al. (2017) found no difference in CP digestibility in lactating dairy cows divergent in RFI, similar to the results for Study 1.

Few studies have evaluated the effect of RFI on mineral digestibility in cattle. For this study, low-RFI heifers had higher $\mathrm{P}, \mathrm{Cu}$, and $\mathrm{Ca}$ digestibilities, but no difference in $\mathrm{Zn}$ digestibility was observed compared with high-RFI heifers. Dias et al. (2016) evaluated the mineral digestibility in pregnant heifers with divergent RFI phenotypes and found conflicting results as they reported higher $\mathrm{Cu}$ and $\mathrm{Zn}$ digestibility, but not $\mathrm{P}$ or $\mathrm{Ca}$ digestibility in low-RFI heifers compared with their high-RFI counterparts. found that $\mathrm{Cu}$ digestibility was higher in low-RFI pregnant heifers.

\section{Dry Matter Intake and Digestibility}

It is generally recognized in ruminants that as DMI increases, DMD decreases, primarily due to the increased rate of passage and a corresponding reduction in rumen retention time associated with higher levels of intake (Staples et al., 1984). Accordingly, mechanisms responsible for variation in DMD of animals with divergent RFI may simply be a function of slower rates of passage through the rumen due to lower DMI of low-RFI animals compared with high-RFI animals, or could be an indication of improved digestive ability of more feed-efficient animals (Kenny et al., 2018). In a recent meta-analysis completed by CantalapiedraHijar et al. (2018), a negative correlation was found between DMD and DMI of animals with divergent RFI, indicating that the increased digestibility of low-RFI animals compared with high-RFI animals may be a direct consequence of lower DMI. However DMI was not found to be a significant covariate for DMD $(P>0.20)$, indicating that the reduction in DMD of high-RFI animals was at least partially independent of DMI. These results are reasonable as the spread in intake as a multiple of maintenance across low- and high-RFI heifers was small (1.7X vs. $2.2 \mathrm{X}$; respectively). On the basis of the assumptions from the NRC (2001), the 0.5 unit increase in intake as a multiple of maintenance observed in this study would correspond to $\sim 2 \%$ reduction in DMD. This does not match the 4\% reduction observed across heifers with divergent RFI in this study, further indicating that part of the variation in DMD may be independent of the level of intake.

These results differ from those reported by Potts et al. (2017) as they found DMI to be a significant covariate when evaluating DMD. However, Nkrumah et al. (2006) pair-fed low- and high-RFI steers and found low-RFI animals to have higher DMD than high-RFI animals. Therefore, when DMI was equal between low- and high-RFI steers, it did not eliminate the relationship between RFI and DMD. Accordingly, part of the variation in DMD of steers with divergent RFI appeared to be independent of DMI, which agrees with the findings of the current study. Furthermore, increased DMI observed in high-RFI animals may reflect an increased need to attain the levels of energy intake required for maintaining $\mathrm{BW}$ and growth.

An additional factor that may affect betweenanimal variation in DMD or RFI is sorting of the diet. In the current study, although daily feed calls were intended to target $10 \%$ feed refusals, high-RFI 
animals had fewer feed refusals as a proportion of DMI, indicating that they may have had less opportunity to sort feed compared with low-RFI animals. However, upon nutrient analysis, no differences were found in the NDF content of feed refusals, and only slight numerical differences were observed in the CP content $(P>0.10)$. Accordingly, it does not appear that between-animal variations in sorting influenced the associations between RFI and DMD in the current study.

For Study 1, the base RFI model (mid-test $\mathrm{BW}^{0.75}$ and ADG) accounted for $54 \%$ of the variation in DMI. When DMD was added to the base model (mid-test $\mathrm{BW}^{0.75}$ and $\mathrm{ADG}$ ), the model $R^{2}$ increased from 0.54 to 0.60 ; thus, DMD accounted for an additional $6 \%$ of the variation in DMI, unaccounted for by mid-test BW ${ }^{0.75}$ or ADG. Similarly, for Study 2, DM and NDF digestibility accounted for an additional $8 \%$ of the variation in DMI, unexplained by mid-test $\mathrm{BW}^{0.75}$ or ADG. When DMD, NDF digestibility, and total VFA were added to the base RFI model for Study 2, trials 2, 3, and 4, the value of $R^{2}$ increased from 0.29 to 0.44 , explaining $15 \%$ of the variation in DMI unrelated to growth and body size. These results are similar to those reported by Herd et al. (2004) as they attributed 14\% of the variation in RFI to differences in digestibility, and further indicating that DMD and ruminal fermentation parameters may contribute to variations in DMI of animals with divergent RFI phenotypes.

\section{Residual Feed Intake and Fermentation Parameters}

Residual feed intake has been evaluated as a strategy for reducing methane emissions as numerous studies have reported significant relationships between methane production and RFI, with low-RFI animals producing less methane per day than their high-RFI counterparts when consuming high-roughage diets (Sharma et al., 2014), highconcentrate diets (Nkrumah et al., 2006; Hegarty et al., 2007), high-quality grazed pasture (Jones et al., 2011) or grass silage (Fitzsimons et al., 2013). However, it is unclear whether differences in $\mathrm{CH}_{4}$ production observed in animals with divergent RFI phenotypes are merely a function of reduced DMI and subsequent reduction in hydrogen available for methanogens, or if there are inherent differences in the digestive efficiency between animals with divergent RFI phenotypes (McDonnell et al., 2016).

While DMI is a strong driver of methane emissions, diet digestibility (Blaxter and Clapperton, 1965) and fiber digestibility (Iqbal et al., 2008) affect methane production, with higher diet or fiber digestibility resulting in less methane loss per unit of GEI. In the current study, DMI was lower, and DMD and NDF digestibility were higher for lowRFI animals compared with their high-RFI counterparts. Subsequently, low-RFI heifers produced $14 \%$ less $(P<0.01)$ methane as a percent of GEI compared their high-RFI counterparts, as estimated by Blaxter and Clapperton (1965). While methane production was not measured in the current study, Nkrumah et al. (2006) found similar results when methane was measured by indirect calorimetry with low-RFI steers producing $25 \%$ less methane GEI than high-RFI steers. Interestingly, in this study, steers were pair-fed so that DMI and GEI were not different across RFI phenotypes, but low-RFI animals had significantly higher (75.3 vs. $70.9 \% ; P<0.05) \mathrm{DM}$, although no differences were observed for NDF digestibilities. Therefore, there were inherit differences in the digestive efficiency between the low- and high-RFI steers that resulted in improved methane GEI for low-RFI animals.

Additional studies have found low-RFI animals to produce less methane per unit of DMI based on a model estimated methane production (Muro-Reyes et al., 2011) or measured methane production using the $\mathrm{SF}_{6}$ technique (Sharma et al., 2014). However, most studies found that low-RFI animals produced numerically higher amounts of methane per unit of DMI consumed (Hegarty et al., 2007; Fitzsimons et al., 2013; McDonnell et al., 2016). These findings suggest that variations in $\mathrm{CH}_{4}$ production observed in animals with divergent RFI phenotypes are merely a function of the reduced DMI associated with low-RFI animals. However, there is evidence to indicate that inherit differences exist between the digestive efficiency of animals with divergent phenotypes, but further research is warranted to examine whether these differences alter methane production per unit of DMI.

The relationship between RFI and ruminal VFA concentrations in cattle have been evaluated in previous studies as summarized by Kenny et al. (2018); however, results have been inconsistent (Guan et al., 2008; Lawrence et al., 2011; Fitzsimons et al., 2013; McDonnell et al., 2016). The current study found only slight alterations in ruminal VFA as low-RFI heifers had lower propionate $(P=0.04)$ and a tendency towards higher A:P ratio $(P=0.09)$ compared with high-RFI heifers. No differences were found between ruminal acetate, butyrate, or total VFA concentrations $(P>0.20)$. In contrast, Guan et al. (2008) found that low-RFI steers fed a high-corn-based diet had a tendency for higher total VFA $(P=0.06)$ and acetate $(P=0.07)$, 
and had higher butyrate $(P<0.001)$ and higher valerate $(P<0.01)$ than their high-RFI counterparts. Additionally, higher $(P=0.05$, Fitzsimons et al., 2013; $P=0.04$, Lawrence et al., 2011) ruminal propionic acid and lower $(P=0.02$, Lawrence et al., 2013) A:P ratios have been reported for low-RFI animals consuming high-roughage diets compared with their high-RFI counterparts.

Guan et al. (2008) used culture-independent PCR-denaturing-gradient gel electrophorese to investigate microbial profiles in the rumen of cattle differing in feed efficiency and found that there was a distinctive microbial clustering between efficient and non-efficient cattle when comparing only Angus profiles, but that clustering was lost when comparing all three breeds (Angus, Charolais, and crossbred). This research may help to explain the inconsistencies between studies as they indicate that VFA concentrations may be dictated by the genetic background of the host in addition to the animals' diet.

In summary, current and previous research suggests that variations in methane production between high- and low-RFI animals involves both diet-animal interactions which alter the balance between the rates of carbohydrate fermentation and passage, and the regulation of hydrogen supply available for subsequent methane production which alters the ratio of VFA produced.

\section{IMPLICATIONS}

Residual feed intake is a useful trait for evaluating mechanism that contributes to betweenanimal variation in feed efficiency, with implications for use in selection programs, as it is independent of growth and body size. However, an improved understanding of the complex biochemical mechanisms regulating RFI is necessary for the continued selection of feed-efficient cattle. In the current study, associations between RFI and DMD were observed, such that low-RFI cattle had increased digestive efficiency of DM compared with high-RFI cattle. Furthermore, differences in apparent DM and NDF digestibility of cattle with divergent RFI phenotypes explained 6 to $8 \%$ of the variation in DMI unexplained by mid-test $\mathrm{BW}^{0.75}$ and ADG. Although the variation in RFI explained by DMD is relatively small, profound impacts exist in regards to production efficiency as increased digestive ability allows animals to consume less feed while maintaining production. If output production is maintained and input costs are reduced, the efficiency of beef cattle production will be improved. More research is needed to elucidate further the relationship between RFI and DM and nutrient digestibility and fermentation parameters in growing beef animals.

Conflict of interest statement. None declared.

\section{LITERATURE CITED}

Allison, M. J., O. R. Mayberry, C. S. McSweeney, and D. A. Stahl. 1992. Synergistes jonesii, genus nov., A rumen bacterium that degrades toxic pyridinediols. Syst. Appl. Microbiol. 15:522-529. doi: 10.1016/ S0723-2020(11)80111-6

ANKOM. 2006a. Acid detergent fiber in feeds filter bag technique. Fairport (NY): Ankom Technology Corporation.

ANKOM. 2006b. Neutral detergent fiber in feeds filter bag technique. Fairport (NY): Ankom Technology Corporation.

Baldassini, W. A., J. J. Ramsey, R. H. Branco, S. F. M. Bonilha, M. R. Chiaratti, A. S. Chaves, and D. P. D. Lanna. 2018. Estimated heat production, blood parameters and mitochondrial DNA copy number of Nellore bulls (Bos indicus) with high and low residual feed intake. Livestock Sci. 217:140-147. doi: 10.1016/j.livsci.2018.10.004

Basarab, J. A., K. A. Beauchemin, V. S. Baron, K. H. Ominski, L. L. Guan, S. P. Miller, and J. J. Crowley. 2013. Reducing GHG emissions through genetic improvement for feed efficiency: Effects on economically important traits and enteric methane production. Animal. 7(Suppl 2):303-315. doi: $10.1017 / \mathrm{S} 1751731113000888$

Blaxter, K. L., and J. L. Clapperton. 1965. Prediction of the amount of methane produced by ruminants. Br. J. Nutr. 19:511-522. doi:10.1079/BJN19650046

Bonilha, S. F. M., R. H. Branco, M. E. Z. Mercadante, J. N. Dos Santos Gonçalves Cyrillo, F. M. Monteiro, and E. G. Ribeiro. 2017. Digestion and metabolism of low and high residual feed intake Nellore bulls. Trop. Anim. Health Prod. 49:529-535. doi:10.1007/ s11250-017-1224-9.

Bryant, M. P., and L. A. Burkey. 1953. Cultural methods and some characteristics of some of the more numerous groups of bacteria in the bovine rumen. J. Dairy Sci. 36(3):205-217. doi: 10.3168/jds.S0022-0302(53)91482-9

Cantalapiedra-Hijar, G., M. Abo-Ismail, G. E. Carstens, L. L. Guan, R. Hegarty, D. A. Kenny, M. McGee, G. Plastow, A. Relling, and I. Ortigues-Marty. 2018. Review: biological determinants of between-animal variation in feed efficiency of growing beef cattle. Animal. 12(Suppl 2):s321-s335. doi:10.1017/S1751731118001489.

Cruz, G. D., J. A. Rodríguez-Sánchez, J. W. Oltjen, and R. D. Sainz. 2010. Performance, residual feed intake, digestibility, carcass traits, and profitability of AngusHereford steers housed in individual or group pens. J. Anim. Sci. 88:324-329. doi:10.2527/jas.2009-1932.

Dias, R. S., Y. R. Montanholi, S. Lopez, B. Smith, S. P. Miller, and J. France. 2016. Utilization of macrominerals and trace elements in pregnant heifers with distinct feed efficiencies. J. Dairy Sci. 99:5413-5421. doi:10.3168/ jds.2015-10796.

Erwin, E. S., G. J. Marco, and E. M. Emery. 1961. Volatile fatty acid analyses of blood and rumen fluid by gas chromatography. J. Dairy Sci. 44:1768-1771. doi: 10.3168/jds. S0022-0302(61)89956-6

Fitzsimons, C., D. A. Kenny, M. H. Deighton, A. G. Fahey, and M. McGee. 2013. Methane emissions, body composition, and rumen fermentation traits of beef heifers 
differing in residual feed intake. J. Anim. Sci. 91:5789 5800. doi:10.2527/jas.2013-6956.

Gomes, R. D., R. D. Sainz, and P. R. Leme. 2013. Protein metabolism, feed energy partitioning, behavior patterns and plasma cortisol in Nellore steers with high and low residual feed intake. Rev. Bras. Zootec. 42(1):44-50.

Guan, L. L., J. D. Nkrumah, J. A. Basarab, and S. S. Moore. 2008. Linkage of microbial ecology to phenotype: Correlation of rumen microbial ecology to cattle's feed efficiency. FEMS Microbiol. Lett. 288:85-91. doi: 10.1111/j.1574-6968.2008.01343.x.

Hafla, A. N., G. E. Carstens, T. D. Forbes, L. O. Tedeschi, J. C. Bailey, J. T. Walter, and J. R. Johnson. 2013. Relationships between postweaning residual feed intake in heifers and forage use, body composition, feeding behavior, physical activity, and heart rate of pregnant beef females. J. Anim. Sci. 91:5353-5365. doi:10.2527/ jas.2013-6423.

Hegarty, R. S., J. P. Goopy, R. M. Herd, and B. McCorkell. 2007. Cattle selected for lower residual feed intake have reduced daily methane production. J. Anim. Sci. 85:1479 1486. doi: 10.2527/jas.2006-236.

Herd, R. M., and S. C. Bishop. 2000. Genetic variation in residual feed intake and its association with other production traits in British Hereford cattle. Livest Prod. Sci. 63(2):111-119. doi: Doi 10.1016/ S0301-6226(99)00122-0

Herd, R. M., V. H. Oddy, and E. C. Richardson. 2004. Biological basis for variation in residual feed intake in beef cattle. 1. Review of potential mechanisms. Aust. J. Exp. Agr. 44(4-5):423-430. doi: 10.1071/Ea02220

Iqbal, M. F., Y. F. Cheng, W. Y. Zhu, and B. Zeshan. 2008. Mitigation of ruminant methane production: Current strategies, constraints and future options. World J. Microb. Biot. 24(12):2747-2755. doi: 10.1007/s11274-008-9819-y

Jones, F. M., F. A. Phillips, T. Naylor, and N. B. Mercer. 2011. Methane emissions from grazing Angus beef cows selected for divergent residual feed intake. Anim. Feed Sci. Tech. 166-67:302-307. doi: 10.1016/j.anifeedsci.2011.04.020

Kayser, W., and R. A. Hill. 2013. Relationship between feed intake, feeding behaviors, performance, and ultrasound carcass measurements in growing purebred Angus and Hereford bulls. J. Anim. Sci. 91:5492-5499. doi:10.2527/ jas.2013-6611.

Kenny, D. A., C. Fitzsimons, S. M. Waters, and M. McGee. 2018. Invited review: improving feed efficiency of beef cattle - the current state of the art and future challenges. Animal. 12:1815-1826. doi:10.1017/S1751731118000976.

Koch, R. M., K. E. Gregory, D. Chambers, and L. A. Swiger. 1963. Efficiency of feed use in beef cattle. J. Anim. Sci. 22(2):486-494.

Lam, S., J. C. Munro, M. Zhou, L. L. Guan, F. S. Schenkel, M. A. Steele, S. P. Miller, and Y. R. Montanholi. 2018. Associations of rumen parameters with feed efficiency and sampling routine in beef cattle. Animal. 12:14421450. doi:10.1017/S1751731117002750.

Lancaster, P. A., G. E. Carstens, F. R. Ribeiro, L. O. Tedeschi, and D. H. Crews, Jr. 2009. Characterization of feed efficiency traits and relationships with feeding behavior and ultrasound carcass traits in growing bulls. J. Anim. Sci. 87(4):1528-1539. doi: 10.2527/jas.2008-1352

Lawrence, P., D. A. Kenny, B. Earley, D. H. Crews, Jr, and M. McGee. 2011. Grass silage intake, rumen and blood variables, ultrasonic and body measurements, feeding behavior, and activity in pregnant beef heifers differing in phenotypic residual feed intake. J. Anim. Sci. 89:32483261. doi:10.2527/jas.2010-3774.

Lawrence, P., D. A. Kenny, B. Earley, and M. McGee. 2012. Grazed grass herbage intake and performance of beef heifers with predetermined phenotypic residual feed intake classification. Animal. 6:1648-1661. doi:10.1017/ S1751731112000559.

Lawrence, P., D. A. Kenny, B. Earley, and M. McGee. 2013. Intake of conserved and grazed grass and performance traits in beef suckler cows differing in phenotypic residual feed intake. Livestock Sci. 152(2-3):154-166. doi: 10.1016/j.livsci.2012.12.024

McDonnell, R. P., K. J. Hart, T. M. Boland, A. K. Kelly, M. Mcgee, and D. A. Kenny. 2016. Effect of divergence in phenotypic residual feed intake on methane emissions, ruminal fermentation, and apparent whole-tract digestibility of beef heifers across three contrasting diets. J. Anim. Sci. 94(3):1179-1193. doi: 10.2527/jas2015-0080

Moore, S. S., F. D. Mujibi, and E. L. Sherman. 2009. Molecular basis for residual feed intake in beef cattle. J. Anim. Sci. 87:E41-47. doi: 10.2527/jas.2008-1418

Muro-Reyes, A., H. Gutierrez-Banuelos, L. H. DiazGarcia, F. J. Gutierrez-Pina, L. M. Escareno-Sanchez, R. Banuelos-Valenzuela, C. A. Medina-Flores, and A. C. Luna. 2011. Potential environmental benefits of residual feed intake as strategy to mitigate methane emissions in sheep. J. Anim. Vet. Adv. 10(12):1551-1556.

Nkrumah, J. D., J. A. Basarab, M. A. Price, E. K. Okine, A. Ammoura, S. Guercio, C. Hansen, C. Li, B. Benkel, B. Murdoch, et al. 2004. Different measures of energetic efficiency and their phenotypic relationships with growth, feed intake, and ultrasound and carcass merit in hybrid cattle. J. Anim. Sci. 82:2451-2459. doi:10.2527/2004.8282 451x.

Nkrumah, J. D., J. A. Basarab, Z. Wang, C. Li, M. A. Price, E. K. Okine, D. H. Crews, and S. S. Moore. 2007. Genetic and phenotypic relationships of feed intake and different measures of feed efficiency with growth and carcass merit of beef cattle. J. Anim. Sci. 85:2711-2720. doi: 10.2527/ jas. 2006-767

Nkrumah, J. D., E. K. Okine, G. W. Mathison, K. Schmid, C. Li, J. A. Basarab, M. A. Price, Z. Wang, and S. S. Moore. 2006. Relationships of feedlot feed efficiency, performance, and feeding behavior with metabolic rate, methane production, and energy partitioning in beef cattle. J. Anim. Sci. 84:145-153. doi: $10.2527 / 2006.841145 x$.

NRC. 2001. Nutrient requirements for dairy cattle. 7 th rev. ed. Washington (DC): The National Academies Press.

Potts, S. B., J. P. Boerman, A. L. Lock, M. S. Allen, and M. J. VandeHaar. 2017. Relationship between residual feed intake and digestibility for lactating Holstein cows fed high and low starch diets. J. Dairy Sci. 100(1):265-278. doi: $10.3168 /$ jds.2016-11079

Richardson, E. C., and R. M. Herd. 2004. Biological basis for variation in residual feed intake in beef cattle. 2. Synthesis of results following divergent selection. Aust. J. Exp. Agr. 44(4-5):431-440. doi: 10.1071/Ea02221

Richardson, E. C., R. M. Herd, J. A. Archer, and P. F. Arthur. 2004. Metabolic differences in Angus steers divergently selected for residual feed intake. Aust. J. Exp. Agr. 44(4 5):441-452. doi: 10.1071/Ea02219 
Richardson, E. C., R. M. Herd, P. F. Arthur, J. Wright, G. Xu, K. Dibley, and V. H. Oddy. 1996. Possible physiological indicators for net feed conversion efficiency in beef cattle. Proc. Aust. Soc. Anim. Prod. 21:103-106.

Rius, A. G., S. Kittelmann, K. A. Macdonald, G. C. Waghorn, P. H. Janssen, and E. Sikkema. 2012. Nitrogen metabolism and rumen microbial enumeration in lactating cows with divergent residual feed intake fed high-digestibility pasture. J. Dairy Sci. 95:5024-5034. doi:10.3168/jds.2012-5392.

Schenkel, F. S., S. P. Miller, and J. W. Wilton. 2004. Genetic parameters and breed differences for feed efficiency, growth, and body composition traits of young beef bulls. Can. J. Anim. Sci. 84(2):177-185. doi: 10.4141/A03-085

Sharma, V. C., M. S. Mahesh, M. Mohini, C. Datt, and V. M. Nampoothiri. 2014. Nutrient utilisation and methane emissions in Sahiwal calves differing in residual feed intake. Arch. Anim. Nutr. 68:345-357. doi:10.1080/17450 39X.2014.951193.

Sharma, V. K., S. S. Kundu, C. Datt, S. Prusty, M. Kumar, and U. B. Sontakke. 2018. Buffalo heifers selected for lower residual feed intake have lower feed intake, better dietary nitrogen utilisation and reduced enteric methane production. J. Anim. Physiol. Anim. Nutr. 102(2):E607-E614. doi: 10.1111/jpn.12802

Staples, C. R., R. L. Fernando, G. C. Fahey, L. L. Berger, and E. H. Jaster. 1984. Effects of intake of a mixed diet by dairy steers on digestion events. J. Dairy Sci. 67(5):9951006. doi: 10.3168/jds.S0022-0302(84)81398-3

Van Soest, P. J., J. B. Robertson, and B. A. Lewis. 1991. Methods for dietary fiber, neutral detergent fiber, and nonstarch polysaccharides in relation to animal nutrition. J. Dairy Sci. 74:3583-3597. doi:10.3168/jds. S0022-0302(91)78551-2.

Vankeulen, J., and B. A. Young. 1977. Evaluation of acidinsoluble ash as a natural marker in ruminant digestibility studies. J. Anim. Sci. 44(2):282-287.

Wilkerson, V. A., D. P. Casper, and D. R. Mertens. 1995. The prediction of methane production of Holstein cows by several equations. J. Dairy Sci. 78:2402-2414. doi:10.3168/ jds.S0022-0302(95)76869-2. 